\title{
INCOME INEQUALITY IN SMALL REGIONS: A STUDY OF AUSTRALIAN STATISTICAL DIVISIONS
}

\author{
Philip Maxwell and Matthew Peter*
}

\section{Introduction}

In the past 30 years many authors have considered the relationship between a country's distribution of income and its stage of economic development. Following the pioneering work of Kuznets (1955), subsequent writers generally have argued that an "inverted U" or "bellshaped" curve results when income levels (horizontal axis) are plotted against income inequality (vertical axis). That is, income inequality rises during the early stages of development, becomes stable, and subsequently falls as development proceeds to high levels. Explanations of this phenomenon are usually couched in terms of unbalanced growth occurring first, followed by progressive economic and social integration, a progession which reduces inequality in the later stages.

If one ascribes to the "bell-shape" hypothesis as a heuristic for understanding development patterns, then it seems likely that the economies of affluent countries would be located on the right-hand side of the bell. One mightexpect, a priori, that empirical observation of a group of such economies would suggest an inverse relationship between income inequality and economic development; yet many such economies have reached a situation in which income inequality has ceased its significant decline. Variations in measures of income inequality will continue over time as a result of factors such as the business cycle, political developments, and demographic trends, but there will be a continuing tendency for inequality to oscillate in a given range. Hence, in Figure 1, the "inverted $U$ " relationship applies between $D_{0}$ and $D_{2}$, but beyond that, as further development proceeds, income inequality will still vary.

While much of the associated empirical analysis has focused on comparisons between nations, it has also been extended to sub-national regions. Kuznets (1963), for example, considered the relationship between mean income levels and several measures of income distribution for a 13-region grouping in Italy in 1948 and for the 48 states of the continental U.S. in 1948 and 1957. Subsequently, there have been a number of other published studies of the relationship between income levels and income inequality among U.S. regions. They include those of Williamson (1965), Al-Samarrie and Miller (1967), *School of Management, Deakin University, Victoria, Australia.
Paukert (1973), Ziegler and Mullendore (1977), and Amos (1985).

In a notable recent study published in this journal, Amos (1986) suggests that while the "inverted U" relationship will exist over a given range, beyond a certain point income inequality among regions in developing nations will increase. In terms of Figure 1, the Kuznets "inverted $U^{\prime \prime}$ applies between development levels $D_{0}$ and $D_{2}$. Between $D_{2}$ and $D_{3}$ income inequality increases again. After explaining this phenomenon in the regional context using growth pole theory, Amos finds empirical support for the "augmented inverted U" at the regional level using crosssectional data from the 1970 U.S. Census.

With the exceptions of the early studies by Kuznets (1963) and Williamson (1965), there has been little empiri$\mathrm{cal}$ analysis of the nature of the relationship between economic development of regions and income inequality in countries outside the U.S. This paper offers such an analysis for Australian sub-state regions. It does so in the context of considering the validity of the "augmented inverted U" hypothesis and the influence of factors such as the business cycle, political issues, and demographic trends, which are likely to cause income inequality to change over time.

\section{Income Inequality and Regional Development in Australia}

Income inequality has fallen significantly in Australia since the 1930s. McLean and Richardson (1986) estimate that between 1933 and 1978-79 the Gini coefficient for family incomes fell from 0.41 to 0.32 . Observation of data from Australian Bureau of Statistics national surveys of income distribution since 1968-69, however, shows that income inequality has not fallen continuously in the past two decades. Published Gini estimates of income for families of two or more people follow:

$\begin{array}{cc}\frac{\text { Year }}{1968-69} & \text { Gini Coefficient } \\ 1973-74 & 0.321 \\ 1978-79 & 0.310 \\ 1981-82 & 0.320 \\ & 0.340\end{array}$

One might interpret these movements as consistent with 
Figure 1

Income Inequality and Development

Income

Inequality

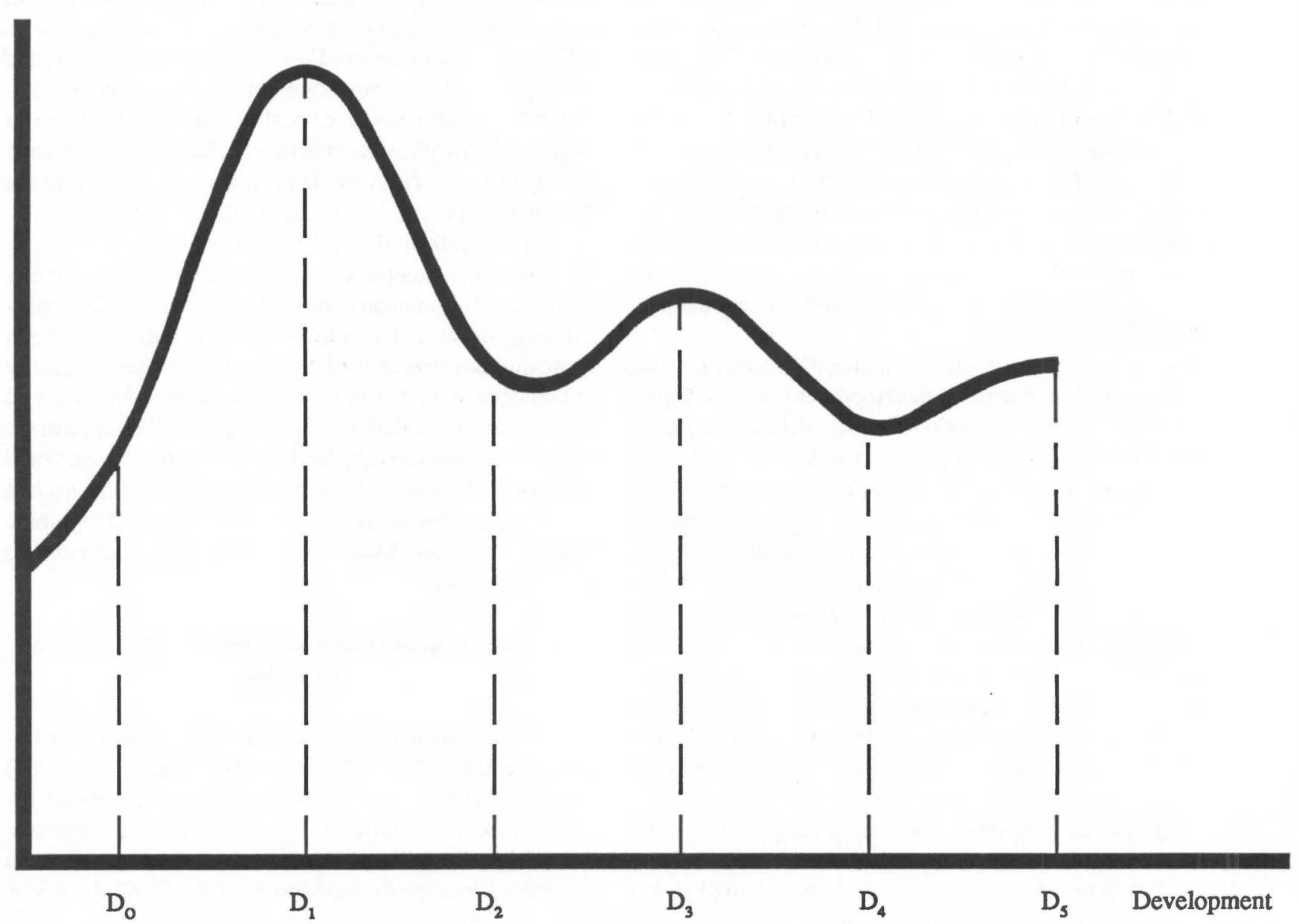


the "inverted U" hypothesis but reflecting, also, the influence of some of the other factors mentioned above.

Moving to a regional perspective, there has long been a perception that differences in economic prosperity in Australian regions are among the smallest in the world. Well-known authors such as Horne (1964) ${ }^{1}$ and Sheehan $(1980)^{2}$ reflect this in their commentaries. In his 1965 paper, mentioned above, Williamson added empirical support to this view. He divided Australia into six regions based on the six states, ${ }^{3}$ and used personal income per capita between 1949-50 and 1959-60 as his income measure. His estimated values for the weighted coefficient of variation $(V w)$ and the mean absolute deviation $(M w)$ were lower for Australian regions than for regions in each of the other 23 countries studied. Both the $V w$ and $M w$ measure have weaknesses because of their emphasis on the variation of means rather than on the entire distribution of income. If one estimates Gini coefficients for family income data, as well as mean incomes, a more comprehensive view emerges.

The Australian Bureau of Statistics has collected and compiled regional income data in the National Census since 1976. ${ }^{4}$ Estimates of the Gini coefficient and mean family incomes for the six Australian states for the 1976 and 1981 Censuses appear in Table 1. In line with Williamson's earlier findings, estimates of $V w$ and $M w$ remain low. Additionally, the Gini estimates vary little between the states. It is notable, however, that the Gini values indicate considerable income inequality within each state ${ }^{4}$ and that their values rose between 1976 and 1981. Mean family incomes also show moderate variations. The two most populous states-New South Wales and Victoria-together with Western Australia, have the highest means for both census dates.

If the states are defined as regions, there seems little evidence of a regional problem in Australia. At a different level of analysis, however, such a problem can be identified. Butler and Mandeville (1981), for example, note that the "high degree of urbanisation, together with the resultant decline and instability in rural areas, is seen by regional economists as "the Australian regional problem." The existence of an imbalance between metropolitan and nonmetropolitan development can be investigated if a consistent regional framework is established at the sub-state level.

In a notable study in the eary 1970 s, the Federal Department of Urban Regional Development (1973) endeavored to provide an authoritative delimitation of substate regions. The Australian Bureau of Statistics has subsequently modified its framework of Statistical Divisions so that it largely reflects this classification. The ABS divides Australia into 57 Statistical Divisions (Figure 2). While other sub-state regional classifications are possible, the ABS framework has merit and is adopted in this paper.

Table 1

Income Inequality Measures for Australia and Its Six States

\begin{tabular}{|c|c|c|c|c|}
\hline & \multicolumn{2}{|c|}{1976 Census } & \multicolumn{2}{|c|}{1981 Census } \\
\hline & $\begin{array}{c}\text { Gini } \\
\text { Coefficient }\end{array}$ & $\begin{array}{l}\text { Mean Family } \\
\text { Income }\end{array}$ & $\begin{array}{c}\text { Gini } \\
\text { Coefficient }\end{array}$ & $\begin{array}{l}\text { Mean Family } \\
\text { Income }\end{array}$ \\
\hline New South Wales & 0.374 & $\$ 9,290$ & 0.423 & $\$ 15,157$ \\
\hline Victoria & 0.372 & 9,577 & 0.406 & 15,009 \\
\hline Queensland & 0.380 & 8,709 & 0.410 & 13,620 \\
\hline South Australia & 0.356 & 9,029 & 0.395 & 13,550 \\
\hline Western Australia & 0.364 & 9,413 & 0.403 & 13,554 \\
\hline Tasmania & 0.370 & 8,793 & 0.403 & 13,554 \\
\hline Australia & 0.373 & 9,323 & 0.414 & 14,779 \\
\hline Vw & & & & \\
\hline Mw & & & & \\
\hline
\end{tabular}


Estimates of Gini coefficients, and mean family incomes for these 57 regions appear in Table 2 for the 1976 and 1981 censuses. At this level there is considerably greater variation between regions in the values of both the Gini index and mean family incomes. In 1976 estimates of the Gini coefficient ranged between 0.320 and 0.465 , while in 1981 corresponding estimates ranged from 0.386 to 0.489. Three of the notable "outliers" in 1976 are Statistical Divisions in Western Australia. They are Midlands, Upper Great Southern and Pilbara. The estimates for the first two are particularly high, and for Pilbara, very low. In the light of estimates for other regions in the state there may be grounds for questioning the validity of these data. If the three regions in question are excluded, the range of Gini coefficients in 1976 is between 0.346 and 0.420 .

The range of mean family incomes was from $\$ 7,250$ to $\$ 14,681$ in 1976 and from $\$ 11,527$ to $\$ 26,167$ in 1981 . It should be noted that in both years the areas with highest estimated mean incomes were the Australian Capital Territory, the Northern Territory, and certain recently developed and isolated mining regions, e.g. Pilbara in Western Australia and North Western in Queensland. The state capital city regions, which one might expect to be most developed, also had high mean family incomes. Costs of living vary between regions, as does the availability of particular services and amenities. If mean family incomes are to be used as an index of development, it seems that some adjustment should be made to reflect this aspect.

While in some countries costs of living tend to be relatively uniform across all regions, this is not the case in Australia. Living costs in remote regions are considerably higher than in the major population centers. The Australian Income Tax Assessment Act identifies about three quarters of Australia's land mass as "remote" and exhibiting uncongenial climatic conditions, isolation, and high costs of living. ${ }^{5}$ Eleven of the ABS Statistical Divisions lie in this area (Figure 2). ${ }^{6}$ Mean income levels in these regions clearly overstate the level of economic development in relation to mean income levels in other sub-state regions.

\section{Explaining Differences in Income Inequality}

In seeking to analyze the empirical relationship between regional income inequality and economic development in Australia following the Kuznets "inverted U" hypothesis, one might initially hypothesize that

$$
\text { inoome inequality }=\mathrm{f}\left(\begin{array}{c}
\text { mean family incomes adjusted } \\
\text { for living costs, rcmoteness }
\end{array}\right) .
$$

The adjusted income variable would reflect in part the stage of development reached in a region. However, remote areas do not possess the same economic infrastructure to support their populations. One might expect higher incomes in isolated areas as a way of compensating trained management and technical personnel for the inadequacy of service facilities available to them. By contrast, long-term residents seem unlikely to demand such incomes. The populations of remote regions may, therefore, experience a more unequal income distribution than their fellow citizens in centrally located regions. ${ }^{7}$

Although regions may have reached similar levels of economic development, they may also experience differences in income inequality because of the influence of political, demographic, social and labor market variables. In the political arena, for example, Labor Party governments at the state level may be more likely to support greater income equality than more conservatively oriented Liberal or National Party governments. Even though federal government policy is of importance in influencing the income distribution, state government initiatives will also affect income inequality within a state's regions. Statistical divisions with larger populations of elderly people might be expected, a priori, to exhibit higher levels of income inequality. In a similar vein, regions with higher than normal percentages of single parent families (or family units headed by females) may experience greater income inequality.

Finally, where the unemployment rate in a region is higher than the national average or labor participation rates are lower, or both, levels of income inequality may be affected. One might hypothesize initially that higher unemployment rates would be associated with greater income inequality in a region. Depressed regions have significant numbers of poor residents, yet it is likely, as well, that there are fewer people in upper income brackets because the affluent and upwardly mobile prefer to live in prosperous regions. If the effect of a lack of high income earners from a region exceeds the unemployment effect, there will be an inverse relationship between income inequality and the rate of unemployment.

Before seeking to specify an empirically testable model, it is necessary to reflect on two other issues. Following Amos's "augmented inverted U" argument, one might expect some regions to experience greater income inequality because of the emergence of secondary growth centers within them. Since capital accumulates at these centers and results in concentrations of capital ownership, differences in income and wealth may increase between the center and periphery. This situation would result in increased income inequality in strongly growing regions. By incorporating a population growth or employment growth variable in a suitable regression model, it is possible to test this hypothesis. 
Figure 2

Australia: Statistical Divisions

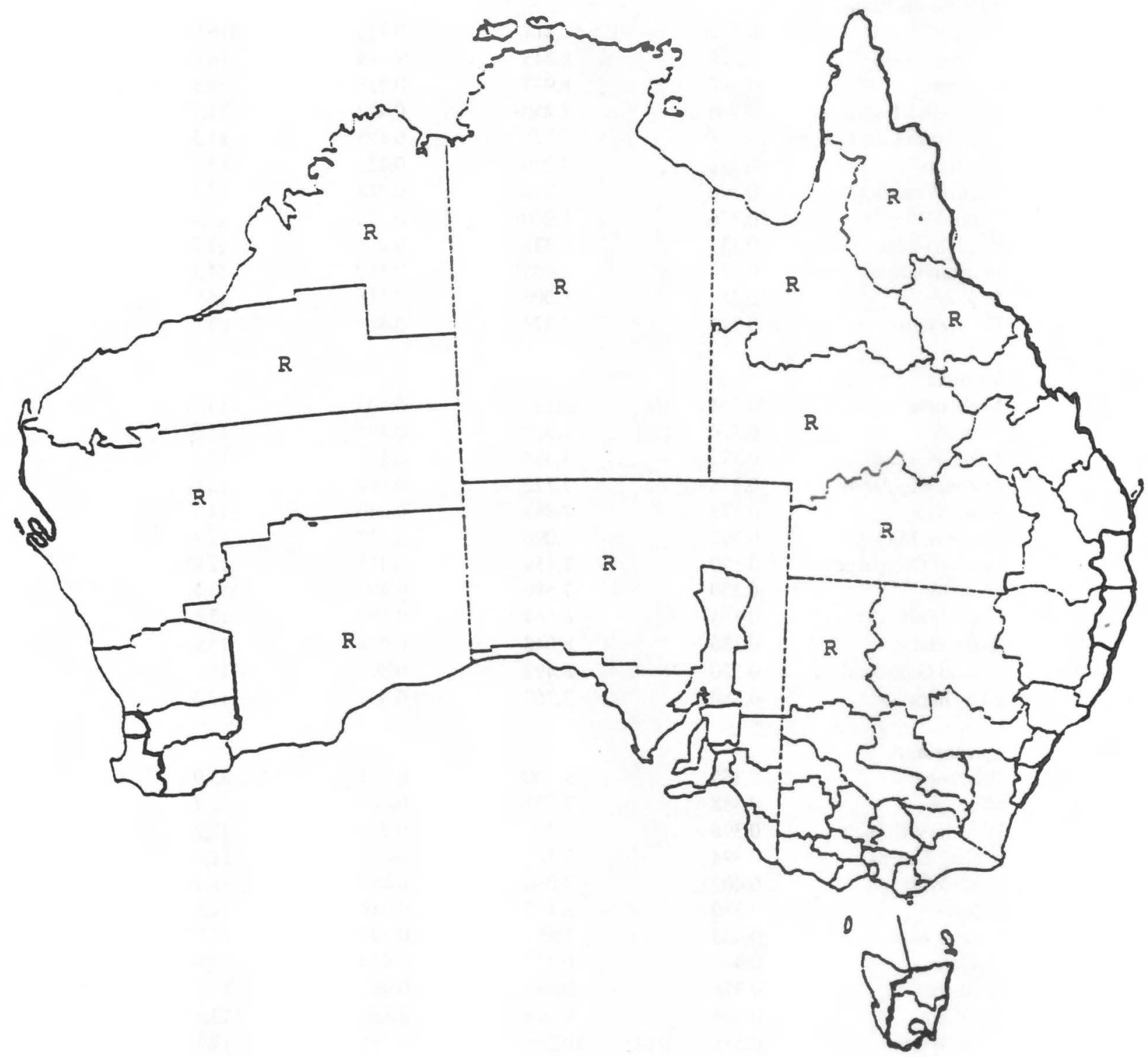


Table 2

Income Inequality Measures for Australian Statistical Divisions

\begin{tabular}{|c|c|c|c|c|}
\hline & \multicolumn{2}{|c|}{1976 Census } & \multicolumn{2}{|c|}{1981 Census } \\
\hline & $\begin{array}{c}\text { Gini } \\
\text { Coefficient }\end{array}$ & $\begin{array}{l}\text { Mean Family } \\
\text { Income }\end{array}$ & $\begin{array}{c}\text { Gini } \\
\text { Coefficient }\end{array}$ & $\begin{array}{l}\text { Mean Family } \\
\text { Income }\end{array}$ \\
\hline \multicolumn{5}{|l|}{ New South Wales } \\
\hline Sydney & 0.373 & $\$ 9,817$ & 0.425 & $\$ 16,094$ \\
\hline Hunter & 0.369 & 8,443 & 0.414 & 14,029 \\
\hline Illawarra & 0.347 & 8,993 & 0.396 & 14,573 \\
\hline Richmond-Tweed & 0.390 & 7,250 & 0.412 & 11,773 \\
\hline Mid-North Coast & 0.378 & 7,278 & 0.405 & 11,527 \\
\hline Northern & 0.391 & 8,250 & 0.426 & 13,397 \\
\hline North Westem & 0.390 & 7,794 & 0.424 & 13,134 \\
\hline Central West & 0.376 & 8,260 & 0.415 & 13,476 \\
\hline South Eastern & 0.372 & 8,337 & 0.413 & 13,265 \\
\hline Murrumbidgee & 0.372 & 8,455 & 0.419 & 14,125 \\
\hline Murray & 0.376 & 8,006 & 0.416 & 14,072 \\
\hline Far Western & 0.375 & 7,924 & 0.416 & 13,256 \\
\hline \multicolumn{5}{|l|}{ Victoria } \\
\hline Melbourne & 0.364 & 10,170 & 0.404 & 15,569 \\
\hline Barwon & 0.370 & 8,669 & 0.395 & 13,574 \\
\hline South Western & 0.383 & 7,388 & 0.415 & 13,164 \\
\hline Central Highlands & 0.378 & 7,722 & 0.407 & 12,588 \\
\hline Wimmera & 0.378 & 7,883 & 0.440 & 14,145 \\
\hline Northern Mallee & 0.392 & 8,096 & 0.427 & 13,662 \\
\hline Loddon-Campaspe & 0.390 & 7,859 & 0.415 & 12,996 \\
\hline Goulburn & 0.380 & 7,580 & 0.409 & 13,829 \\
\hline North Eastern & 0.375 & 8,164 & 0.387 & 13,432 \\
\hline East Central & 0.380 & 8,048 & 0.438 & 13,942 \\
\hline Central Gippsland & 0.370 & 8,492 & 0.395 & 15,280 \\
\hline East Gippsland & 0.380 & 7,360 & 0.394 & 12,476 \\
\hline \multicolumn{5}{|l|}{ Queensland } \\
\hline Brisbane & 0.365 & 9,106 & 0.397 & 13,935 \\
\hline Moreton & 0.388 & 7,627 & 0.418 & 12,723 \\
\hline Wide Bay-Burnett & 0.396 & 7,731 & 0.430 & 11,926 \\
\hline Darling Downs & 0.394 & 7,736 & 0.420 & 12,415 \\
\hline South West & 0.402 & 7,036 & 0.449 & 12,454 \\
\hline Fritzroy & 0.380 & 8,477 & 0.416 & 14,336 \\
\hline Central West & 0.408 & 7,651 & 0.447 & 12,996 \\
\hline Mackay & 0.420 & 10,677 & 0.470 & 17,044 \\
\hline Northern & 0.376 & 9,490 & 0.403 & 14,231 \\
\hline Far North & 0.394 & 8,496 & 0.429 & 13,347 \\
\hline North Westem & 0.351 & 10,296 & 0.415 & 17,215 \\
\hline \multicolumn{5}{|l|}{ South Australia } \\
\hline Adelaide & 0.353 & 9,302 & 0.394 & 13,634 \\
\hline Outer Adelaide & 0.372 & 7,619 & 0.399 & 12,743 \\
\hline Yorke \& Lower North & 0.391 & 7,936 & 0.429 & 12,843 \\
\hline Murray Lands & 0.355 & 7,904 & 0.402 & 12,819 \\
\hline South East & 0.346 & 8,235 & 0.389 & 13,997 \\
\hline Eyre & 0.373 & 8,990 & 0.429 & 14,536 \\
\hline Northern & 0.338 & 8,807 & 0.386 & 13,665 \\
\hline
\end{tabular}




\begin{tabular}{|c|c|c|c|c|}
\hline \multicolumn{5}{|l|}{ Western Australia } \\
\hline Perth & 0.357 & 9,380 & 0.400 & 14,753 \\
\hline South West & 0.361 & 7,722 & 0.400 & 13,390 \\
\hline Lower Great Southern & 0.374 & 8,430 & 0.433 & 14,820 \\
\hline Upper Great Southern & 0.434 & 11,049 & 0.489 & 17,905 \\
\hline Midlands & 0.465 & 11,772 & 0.447 & 15,668 \\
\hline South East & 0.358 & 8,724 & 0.418 & 15,159 \\
\hline Central & 0.378 & 9,767 & 0.431 & 14,934 \\
\hline Pilbara & 0.320 & 14,586 & 0.461 & 26,167 \\
\hline Kimberley & 0.389 & 9,591 & 0.469 & 14,983 \\
\hline \multicolumn{5}{|l|}{ Tasmania } \\
\hline Hobart & 0.372 & 9,642 & 0.407 & 14,406 \\
\hline Southern & 0.368 & 7,043 & 0.416 & 11,854 \\
\hline Northern & 0.365 & 8,157 & 0.397 & 12,854 \\
\hline Mersey-Lyell & 0.360 & 8,567 & 0.395 & 13,402 \\
\hline \multicolumn{5}{|l|}{ Australian } \\
\hline Capital Terrltory & 0.391 & 14,681 & 0.457 & 22,109 \\
\hline Northern Territory & 0.411 & 11,462 & 0.464 & 18,895 \\
\hline Vw & \multicolumn{2}{|c|}{0.262} & \multicolumn{2}{|c|}{0.116} \\
\hline Mw & \multicolumn{2}{|c|}{10.154} & \multicolumn{2}{|c|}{8.55} \\
\hline
\end{tabular}

A second issue concerns whether it is possible to adjust the mean family income data reported in Table 2 above to arrive at "real" income measures which reflect the level of economic development in all regions. While the $\mathrm{ABS}$ does compile a set of experimental index numbers for the relative retail prices of food across Australia, there are no comprehensive calculations of living costs in other areas of the Consumer Price Index basket. ${ }^{8}$ In the absence of such data it would seem advisable to use a measure other than adjusted income as a proxy for economic development in any statistical analysis. ${ }^{9}$ Possible alternatives include percentage service sector employment, percentage white collar employment and percentage of the population over 15 years of age with post-school qualifications. High values of the first two variables may reflect a higher level of regional development.

However, regions with strong agricultural or mining bases and lower service sector employment are not necessarily less developed than their urban counterparts. Because of this, the third variable-percentage of the population over 15 years of age with post-school qualifications-seemed more appropriate as the development variable in our regressions. This variable includes people holding degress, diplomas, technician certificates and trade certificates.

In the empirical analysis which follows we specify a model of the general form, income inequality $=\mathrm{f}\left(\begin{array}{c}\text { development proxy variable, labor makkt oon- } \\ \text { ditions, demogrephic characteristics, political } \\ \text { dimste, remoteness, employment change }\end{array}\right)$.

Ordinary least squares regression estimates of different forms of this model appear in Table 3 below for both the 1976 and 1981 census data. The specific form of the model in Table 3 is:

$G=a+b_{1} P S Q+b_{2} U+b_{3} A 65+b_{4} S P F+b_{5} Y C G+b_{6} R+b_{7} E G+u$, where

$$
\begin{aligned}
& \mathrm{G}= \text { estimated value of the Gini coefficient, } \\
& \mathrm{PSQ}= \text { percentage of population over } 15 \text { years of } \\
& \text { age with post-school qualifications, } \\
& \mathrm{U}= \text { Unemployment rate, } \\
& \mathrm{A} 65= \text { percentage of the population over } 65 \text { years } \\
& \text { of age, }
\end{aligned}
$$

In the light of the preceding discussion, one might 
expect estimated $b$ coefficients to have the following signs:

$$
\begin{array}{r}
\text { PSQ: - } \\
\text { U: - } \\
\text { A65: + } \\
\text { SPF: + } \\
\text { YCG: + } \\
\text { R: + } \\
\text { EG: +. }
\end{array}
$$

Since we are presumably on the right-hand side of the "bell curve," the influence of post-school qualifications on income distribution might be expected to be negative and to be declining over time. As can be seen from Table 3, post-school qualifications, the percentage of single-person families, state government political bias, the remoteness dummy, and recent employment growth exhibit the expected arithmetic signs for their coefficient estimates for both the 1976 and 1981 data. In 1976 all of these estimates were significant at either the five per cent or one per cent level. The age variable, A65, did not exhibit the expected coefficient sign in either year.

It is particularly notable that the recent employment growth variable was a significant explanatory variable in 1976 and 1981 and that its coefficient was positive on both occasions. This observation lends empirical support for
Amos' contention that accelerating economic development in a region will be associated with increased income inequality. In this sense it is consistent with his "augmented inverted U" hypothesis. However, our findings are also consistent with the view that regional variations in income inequality will be influenced by a series of factors independent of the economic development process, such as business cycles, political developments, demographic trends, etc. One might interpret our cross-sectional estimates as reflecting Australian sub-state regions being positioned within a range between $D_{2}$ and $D_{4}$ in Figure 1 above.

Also of note in both the equations of Table 3 is the negative coefficient of the unemployment variable and its statistical significance in 1981. Our hypothesis above is consistent with the fact that depressed regions will experience less income inequality because high income earners prefer to live elsewhere. This effect apparently is stronger than the opposite effect which high unemployment rates will have in increasing income inequality.

\section{Summary and Conclusion}

The availability of data on incomes from the national censuses in 1976 and 1981 has enabled new insights into patterns of income distribution in Australian regions.

Table 3

Estimated Values of Regression Coefficients of Single Equation-OLS Models Explaning Variations in Gini Indices: Australian Statistical Divisions 1976 and 1981

\begin{tabular}{lcc}
\hline \hline Independent Variable & 1976 & 1981 \\
\hline Post-School Qualifications & $-0.00316^{*}$ & -0.00171 \\
Unemployment Rate & -0.00249 & $-0.00423^{* *}$ \\
Percent Over 65 Years of Age & -0.000722 & $-0.00389^{*}$ \\
Percent Single-Parent Families & $0.00286^{* *}$ & -0.000553 \\
State Government Political Bias & $0.00437^{*}$ & 0.000665 \\
Remoteness & $-0.000489^{* *}$ & 0.000409 \\
Recent Employment Growth & $0.000631^{* *}$ & 0.000761 \\
& & \\
Intercept & 0.343 & 0.493 \\
Adjusted $\mathrm{R}^{2}$ & 0.302 & 0.299 \\
\hline \hline
\end{tabular}

*significant at one percent level

**significant at five percent level 
While there are small differences in Gini coefficients and mean family incomes between the states, considerable variation occurs between the sub-state statistical divisions. Higher mean incomes occur in remote regions, particularly in recognition of the higher living costs and isolation of residents.

The pioneering intracountry analysis of Kuznets provides a convenient starting point in assessing the relationship between economic development and income distribution. In a sub-national regional framework, such as that of Australia's Statistical Divisions, however, factors other than economic development alone influence estimates of income inequality. Our single equation regression models suggest that labor market conditions, family structure, the conservative or labor bias of recent state governments and geographic remoteness are variables which influence regional income distribution.

Although based on a different empirical model, the findings of this study are also consistent with those of Amos (1986) for sub-state and SMSA personal income inequality in the U.S., insofar as they support the contention that accelerated regional development, due to growth pole activity, is associated with greater income inequality.

\section{Notes}

${ }^{1}$ Horne remarks: ".... there are more cars and TV sets than anywhere except North America and a refrigerator in all but three per cent of households; there is the largest rate of home ownership in the world; there are more savings accounts than people. Even these figures do not give an idea of Australia's economic equality. Not only are very rich or very poor people rare; the average income is not just a simple average, it is also close to the typical income."

2Sheehan noted: "Australia's self-image remains that of a nation of freedom and equality, where the good things of life are more evenly distributed than in other countries and where there is as much room to move in economic and social terms as there is in geographical ones."

${ }^{3}$ Williamson included data for the Australian Capital Territory with New South Wales and data for the Northem Territory with South Australia.

"It should be noted that data collection procedures in national surveys differ from those in the Census. In the former, interviewers are involved in obtaining data directly from the sample. In the latter, all family units provide data by completing Census questionnaires without the guidance of trained interviewers. The former method is likely to lead to more accurate estimates of the distribution of income.

${ }^{5}$ For further discussion of this point see Report of the Public Inquiry into Income Tax Zone Allowances; Canberra: AGPS, 1981.

These remote regions are Far Western (NSW), South West (Qld), Central West (Qld), North Western (Qld), Far North (Qld), Northern Territory, South East (WA), Central (WA),
Pilbara (WA) and Kimberly (WA).

'See Alonso (1968; 5-6) for further discussion of this issue.

'For a general discussion in this area see Beattie and McLoughlin (1983).

'Another approach would be to exclude all remote regions and any other high cost of living regions from the analysis.

This approach would reduce the sample of regions for analysis from 57 to less than 46 .

\section{References}

Alonso, William. "Urban and Regional Imbalances in Economic Development." Economic Development and Cul tural Change. 17 (1968). 1-14. - "Five Bell Shapes in Development." Regional Science Association Papers. 45 (1980). 5-16.

Al-Sammarie, A. and H. P. Miller. "State Differentials in Income Concentration." American Economic Review. 57 (1967). 59-71.

Amos, O. M. Jr. "The Relationship between Regional Income Inequality, Personal Income Inequality, and Development." Regional Science Perspectives. (1985). 3-14. "Substate and SMSA Personal Income Inequality and Regional Development." The Review of Regional Studies. 16:2 (Spring 1986). 23-30.

Australian Bureau of Statistics. Census of Population and Housing. Canberra, Australia: AGPS, 1976. . Census of Population and Housing. Canberra, Australia: AGPS, 1981.

Beattie, D., and P. McLoughlin. "Relative Costs in Remote Areas." Social Security Journal. (1983). 36-48.

Butler, G. and T. Mandeville. Regional Economics: An Australian Introduction. Brisbane, Australia: University of Queensland Press, 1981.

Department of Urban and Regional Development. Regions. Canberra, Australia: 1973.

Maxwell, P. and M. Peter. "Income Inequality in Regional Labour Markets: A Study of Australian Census Data, 1976-1981." Papers of the Regional Science Association, Australia \& New Zealand Section. (1986). 48-60.

McLean, I. and S. Richardson. "More or Less Equal? Australian Income Distribution in 1933 and 1980." The Economic Record. 62 (1986). 67-81.

Paukert, F. "Income Distribution at Different Levels of Development: A Survey of Evidence." International Labour Review. 108 (1973). 97-125.

Sheehan, P. Crisis in Abundance. Ringwood, Victoria: Penquin Books, 1980.

Williamson, J. "Regional Inequality and the Process of National Development: A Description of the Patterns." Economic Development and Cultural Change. 13 (1965). 384.

Ziegler, L. F. and W. E. Mullendore. "Variations in Income Distribution Among the State Planning Regions of Texas." Journal of Regional Science. 17:2 (1977). 271-286. 